\title{
Virtual multidisciplinary team meetings in the age of COVID-19: an effective and pragmatic alternative
}

\author{
Jai Sidpra $^{1}$, Sahil Chhabda ${ }^{2}$, Celia Gaier ${ }^{1}$, Anoushka Alwis ${ }^{3}$, Neetu Kumar ${ }^{4}$, Kshitij Mankad $^{2}$ \\ ${ }^{1}$ University College London Medical School, London, UK; ${ }^{2}$ Department of Radiology, ${ }^{3}$ Department of Neurology, ${ }^{4}$ Department of Urology, Great \\ Ormond Street Hospital for Children, London, UK
}

Correspondence to: Kshitij Mankad, FRCR. Department of Radiology, Great Ormond Street Hospital for Children, London, WC1N 3JH, UK. Email: kshitij.mankad@gosh.nhs.uk.

Provenance and Peer Review: This article was commissioned by the editorial office, Quantitative Imaging in Medicine and Surgery. The article did not undergo external peer review.

Submitted May 05, 2020. Accepted for publication May 25, 2020.

doi: 10.21037/qims-20-638

View this article at: http://dx.doi.org/10.21037/qims-20-638

The ongoing severe acute respiratory syndrome coronavirus 2 (SARS-CoV-2) pandemic and the associated coronavirus disease 2019 (COVID-19) have had a profound global and individual burden, with 1,610,909 confirmed cases and 99,690 confirmed deaths across 213 countries, areas, and territories at the time of writing (1).

The highly transmissible nature of the novel coronavirus, its potential for asymptomatic transmission, and the lack of a curative treatment, has necessitated the enforcement of stringent social distancing and quarantine measures in order to limit the rate of infection-thereby reducing morbidity and mortality whilst also reducing the strain on rapidly saturating healthcare systems (2).

Recent literature has identified that medical professionals account for COVID-19 patients due to their increased and repeated exposure to the virus (3). This unhappy truth, combined with a lack of testing and personal protective equipment for key workers, has, in some areas, seen a diminishment of the workforce and a reduction of our ability to combat the disease on both a local and international level (4).

Multidisciplinary team meetings (MDTs) are defined by the United Kingdom's National Health Service as 'a group of professionals from one or more clinical disciplines who together make decisions regarding recommended treatment of individual patients' (5). They have become the clinical mainstay and gold-standard for the care of complex patients, in particular those with oncological malignancies. As such, their efficacy and cost-effectiveness is well documented in the literature (6-8).

In this light, as MDTs in their current format necessitate face-to-face contact between multiple clinical teams, they have the potential to act as potent accelerators of viral transmission. This article evaluates the efficacy of virtual MDTs in the light of the SARS-CoV-2 pandemic as a means of reviewing patient care at a physical distance, thereby maintaining the safety of clinicians by minimizing the risk of infection.

We conducted a survey of 50 practicing physicians who have been using virtual MDTs since mid-March of the SARS-CoV-2 pandemic (1 month at the time of writing). This evaluated their thoughts on whether or not virtual MDTs are a safe alternative to in-person MDTs and on how the shift to a virtual space may have affected the standard of patient care. This was achieved through comparison of opinions of virtual MDTs to in-person MDTs across eleven core criteria: accessibility; clinical decision process and consensus; clinical governance; communication; continuity

^Jai Sidpra, ORCID: 0000-0003-1985-5503; Kshitij Mankad, ORCID: 0000-0001-5979-9337. 


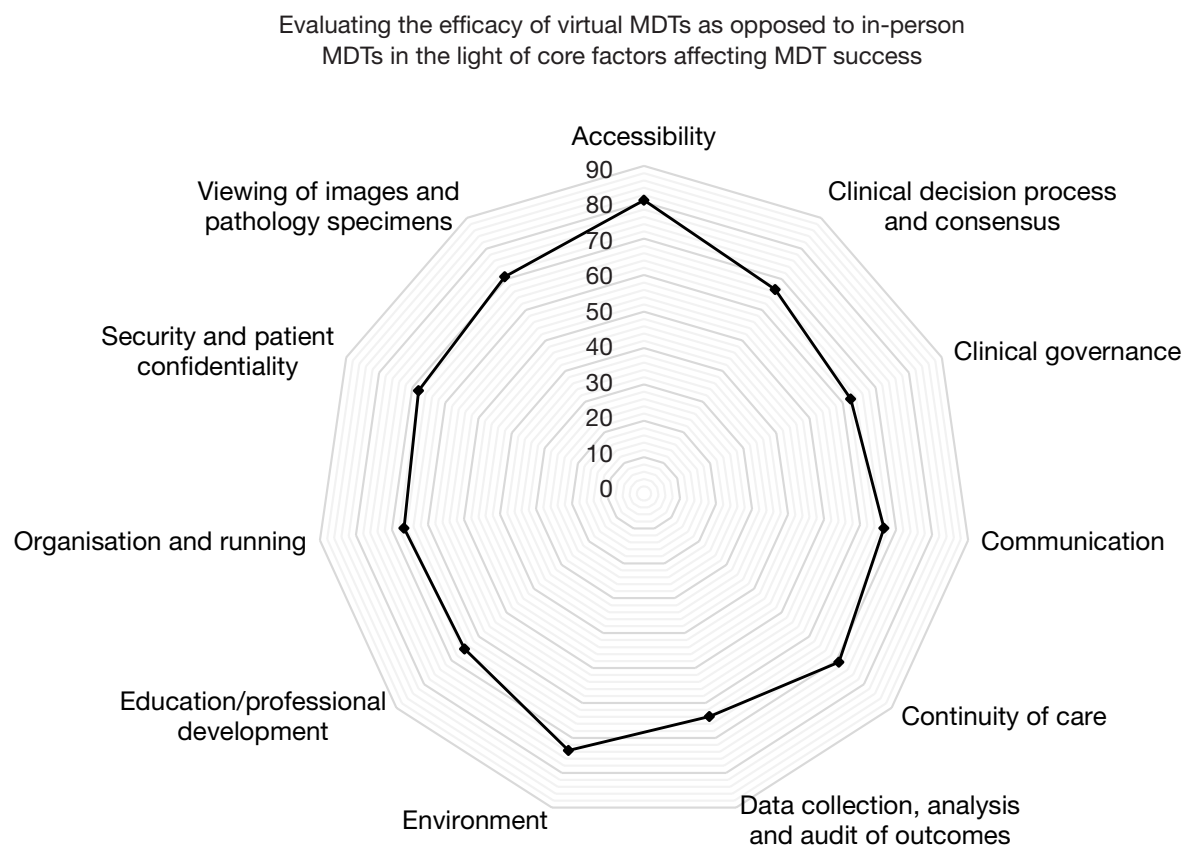

Figure 1 A radar plot evaluating how core aspects of virtual multidisciplinary team meetings (MDTs) compare to standard face-to-face MDTs.

of care; data collection, analysis, and audit of outcomes; environment; education and professional development; organization and running; security and patient confidentiality; and the viewing of images and pathology specimens. Our core criteria was informed by analyses in the literature in addition to Munro et al.'s 2013 framework for virtual MDTs $(9,10)$. In addition to the above, we asked participants which videoconferencing software they had used for the purpose of virtual MDTs and, of those used, which they preferred.

We received 24 responses to our survey which corresponds to $48 \%$ of those surveyed. Respondents included both clinicians (46\%) and radiologists (54\%) at all stages of their careers from both the United Kingdom (58\%) and the United States (42\%). Our cohort attended a median of 4 MDTs per week (mean: 4.4 , mode: 4 , range: 8 ). There was no significant difference between the number of MDTs attended by clinicians and the number of MDTs attended by radiologists, though consultants were found to attend more MDTs (median: 5) than their more junior colleagues (median: 3.5). We found that the vast majority (83.3\%) of those surveyed reported that virtual MDTs provide the same standard of care as face-to-face MDTs and that twothirds would support the use of virtual MDTs following the end of the current pandemic and the ensuing return to normal work. In addition, the majority reported that virtual
MDTs perform equal to or better than their in-person counterpart across all factors deemed intrinsic to the success of an MDT (Figure 1). The most commonly used software for the hosting of virtual MDTs was Zoom (53\%), though GoToMeeting and BlueJeans also featured prominently ( $24 \%$ and $18 \%$ respectively). Other platforms were used significantly less (5\%). Of the platforms used, $91 \%$ found Zoom to be the most suited to use.

The use of virtual MDTs is well documented in the literature across a number of medical specialties. As supported by our findings, they have been noted to remove geographic barriers in addition to facilitating clinical communication and decision making. They have also been described in the context of reducing healthcare inequality by increasing access to specialist centers, particularly in the developing world (11). This said, some concern remains regarding the quality of the communication, with $42 \%$ of those surveyed stating that they prefer inperson communication as it 'builds stronger relationships', 'encourages more robust conversation', and allows for the 'detection of non-verbal cues'. Difficulties with technology and connectivity are also frequently reported as significant areas of concern, though these were not reported by our cohort (12).

Notably, a third of respondents found the virtual environment to be better than the physical environment 
and that it encouraged more durable, organized chairing which in turn reduced the number of people speaking at any one time. Additionally, a significant majority (91.7\%) found the viewing of images and histological samples to be equal or better in the virtual space whilst $100 \%$ stated that continuity of care was equal or better, dispelling claims that the use of videoconferencing may be disruptive to clinical care.

The choice of platform is fundamental to the success of a virtual MDT. Though Zoom was found to be the most favored of those surveyed, it does not currently use endto-end encryption for videoconferencing and so may leave patient data vulnerable. In addition, platforms have recently been subject to outbreaks of malicious activity aiming at the sharing of hate speech and pornographic material. Hence, the security of any platform should be stringently tested before patient identifiable information is exchanged across it (13).

The potential to integrate decision-making aids and artificial intelligence workflows into future MDT software is a key area of development which may transform the MDT landscape in terms of the automated screening of patients for clinical trials and the highlighting of more complex cases to allow for better time-management, itself a key concern for the surgical team $(12,14)$.

We acknowledge that these results describe a relatively small cohort though find them to be reflective of the wider literature on the subject. Therefore, though self-reported, we believe the opinions given to be honest, accurate, and of value. In addition, as all respondents were of varying seniority across the clinical and radiological specialties, we believe our findings to be generalizable to the MDT at large.

During such unprecedented times as those of the ongoing SARS-CoV-2 pandemic, adaptations to standard clinical practice must be made in order to minimize the rate of infection and the spread of the associated disease, COVID-19. In this light, virtual MDTs should be seen as an effective and pragmatic tool that can be employed to minimize interpersonal contact and the potential for viral transmission. However, we also posit that, in our increasingly small and interconnected world, virtual MDTs will become a standard component of future clinical workflows.

\section{Acknowledgments}

Funding: None.

\section{Footnote}

Conflicts of Interest: All authors have completed the ICMJE uniform disclosure form (available at http://dx.doi. org/10.21037/qims-20-638). KM serves as an unpaid Associate Editor of Quantitative Imaging in Medicine and Surgery. The other authors have no conflicts of interest to declare.

Ethical Statement: This service evaluation was approved by the institutional review board (reference number 2835). Survey participants were consented before participation.

Open Access Statement: This is an Open Access article distributed in accordance with the Creative Commons Attribution-NonCommercial-NoDerivs 4.0 International License (CC BY-NC-ND 4.0), which permits the noncommercial replication and distribution of the article with the strict proviso that no changes or edits are made and the original work is properly cited (including links to both the formal publication through the relevant DOI and the license). See: https://creativecommons.org/licenses/by-nc-nd/4.0/.

\section{References}

1. World Health Organization. Coronavirus disease 2019 (COVID-19) Situation Report - 82. 2020. Available online: https://www.who.int/docs/default-source/coronaviruse/ situation-reports/20200411-sitrep-82-covid-19.pdf

2. Ferguson NM, Laydon D, Nedjati-Gilani G, Imai N, Ainslie K, Baguelin M, Bhatia S, Boonyasiri A, Cucunubá Z, Cuomo-Dannenburg G, Dighe A, Dorigatti I, Fu H, Gaythorpe K, Green W, Hamlet A, Hinsley W, Okell LC, van Elsland S, Thompson H, Verity R, Volz E, Wang H, Wang Y, Walker PGT, Caroline Walters C, Winskill P, Whittaker C, Donnelly CA, Steven Riley S, Ghani AC. Impact of non-pharmaceutical interventions (NPIs) to reduce COVID-19 mortality and healthcare demand. Imperial College London 2020. doi: 10.25561/77482.

3. The Lancet. COVID-19: protecting health-care workers. Lancet 2020;395:922.

4. Kuchler H. Coronavirus testing shortages: what's the problem? Financial Times 2020. Available online: https://www.ft.com/content/86efe246-692e-11ea-800dda70cff6e $4 d 3$

5. United Kingdom National Health Service. Multidisciplinary Team. NHS Business Definitions 2019. Available online: https://www.datadictionary.nhs.uk/data 
dictionary/nhs_business_definitions/m/multidisciplinary_ team_de.asp?shownav=1

6. United Kingdom National Health Service. Achieving world-class cancer outcomes: a strategy for England 20152020. 2016. Available online: https://www.england.nhs. $\mathrm{uk} /$ publication/achieving-world-class-cancer-outcomes-astrategy-for-england-2015-2020/

7. Prades J, Remue E, van Hoof E, Borras JM. Is it worth reorganising cancer services on the basis of multidisciplinary teams (MDTs)? A systematic review of the objectives and organisation of MDTs and their impact on patient outcomes. Health Policy 2015;119:464-74.

8. European Commission for Health and Food Safety. State of Health in the EU Companion Report 2017. 2017. Available online: https://euagenda.eu/upload/publications/ untitled-152858-ea.pdf

9. Munro AJ, Swartzman S. What is a virtual multidisciplinary team (vMDT)? Br J Cancer 2013;108:2433-41.

10. Jalil R, Ahmed M, Green JS, Sevdalis N. Factors that can make an impact on decision-making and decision

Cite this article as: Sidpra J, Chhabda S, Gaier C, Alwis A, Kumar N, Mankad K. Virtual multidisciplinary team meetings in the age of COVID-19: an effective and pragmatic alternative. Quant Imaging Med Surg 2020;10(6):1204-1207. doi: 10.21037/qims20-638 implementation in cancer multidisciplinary teams: an interview study of the provider perspective. Int J Surg 2013;11:389-94.

11. Augestad KM, Lindsetmo RO. Overcoming distance: video-conferencing as a clinical and educational tool among surgeons. World J Surg 2009;33:1356-65.

12. Taylor C, Ramirez A, National Cancer Action Team MDT Development Programme. Multidisciplinary team members' views about MDT working: Results from a survey commissioned by the National Cancer Action Team. 2009. Available online: http://www.ncin.org.uk/ view? rid= 137

13. Paul K. 'Zoom is malware': why experts worry about the video conferencing platform. The Guardian 2020. Available online: https://www.theguardian.com/ technology/2020/apr/02/zoom-technology-securitycoronavirus-video-conferencing

14. Taylor C, Shewbridge A, Harris J, Green JS. Benefits of multidisciplinary teamwork in the management of breast cancer. Breast Cancer (Dove Med Press) 2013;5:79-85. 